\title{
Exploratory Study of Glowing Electrical Connections
}

William J. Meese

and Robert W. Beausoliel

Building Services Section

Building Environment Division

Center for Building Technology

National Bureau of Standards

Washington, D. C. 20234

October, 1976

Final Report

Prepared for

Office of Policy Development and Research Department of Housing and Urban Development Washington, D. C. 20410 



\section{EXPLORATORY STUDY OF GLOWING ELECTRICAL CONNECTIONS}

William J. Meese

and Robert W. Beausoliel

Building Services Section

Building Environment Division

Center for Building Technology

National Bureau of Standards

Washington, D. C. 20234

October, 1976

Final Report

Prepared for

Office of Policy Development and Research

Department of Housing and Urban Development

Washington, D. C. 20410

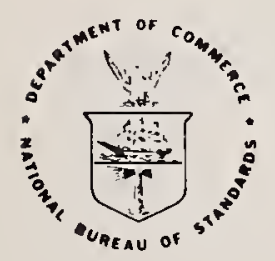

U.S. DEPARTMENT OF COMMERCE, Elliot L. Richardson, Secretary

Edward O. Vetter, Under Secretary

Dr. Betsy Ancker-Johnson, Assistant Secretary for Science and Technology

NATIONAL BUREAU OF STANDARDS, Ernest Ambler, Acting Director 

In view of the present accepted practice in this cou: try for building technology, common U.S. units of measurement have been used throughout this document. In recognition of the position of the United States as a signatory to the General Conference on Weights and Measures, which gave official status to the metric SI system of units in 1960 , assistance is given to the reader interested in making use of the coherent system of SI units by giving conversion factors applicable to U.S. units used in this document.

\section{Length}

$$
1 \text { in }=0.0254 * \text { meter }(\mathrm{m})
$$

Temperature

$$
t_{O_{C}}=5 / 9\left(t_{O_{F}}-32\right) *
$$

Torque

1 in-1b $=0.113 *$ meter-newtons

* Exactly 


\section{ABSTRACT}

This report describes and characterizes with quantifiable electrical and thermal measures the extent to which loose electrical connections in residential-type branch circuits have overheated in the laboratory. With loose electrical connections, which conceivably could be inadvertently duplicated in field installations, but with otherwise normal installation and operating conditions, visible glows have been observed under laboratory test conditions in nominal 120 volt, 15 and 20 ampere branch circuits with both copper and aluminum wire. Characteristics of the glow condition are differentiated from arcing/sparking as sometimes observed in making or breaking electric circuits.

Glowing electrical connections may dissipate as much as 35 watts of power with a current of 15 amps in the circuit and as much as 5 watts with a current of $0.8 \mathrm{amp}$ in the circuit. Temperatures over $750^{\circ} \mathrm{F}$ were measured on the "break-off tab" of receptacles. Metal outlet boxes housing glowing connections in an insulated wall test set-up representative of a common type of residential construction attained temperatures in excess of $450^{\circ} \mathrm{F}$. In laboratory tests under repetitive, intermittent and periodic cycles, a connection on a steel wire-binding screw of a receptacle open to the air had sustained glow conditions maintained for over 100 hours. Glowing connections will not perceptibly affect the electrical performance function of lights, appliances or other electrical loads, and will not "blow" fuses, trip circuit breakers or operate ground fault circuit interrupters.

Key Words: Arcing/sparking; branch circuit; contact resistance; electrical connections; fire hazard; glowing electrical connections 


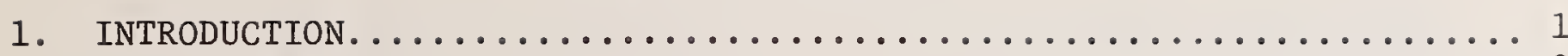

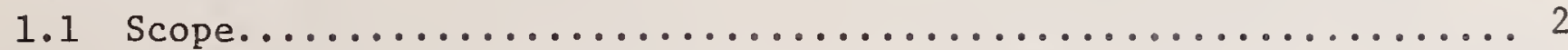

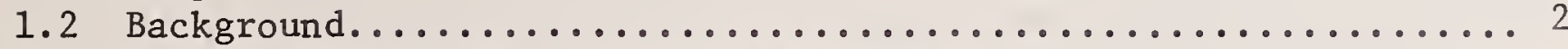

1.3 Use of Term "Glow" or "Glow Discharge" in Electrical Theory.............................. 2

1.4 Definition of Glow as Used in this Report................ 2

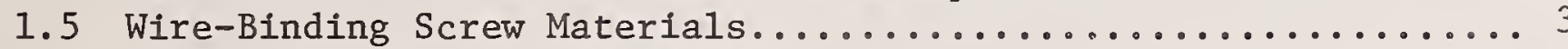

2. Description of Arcing/Sparking in Electrical Circuits........... 3

3. Description of the Glow Condition ...................... 4

3.1 General Parameters of Glow Electrical Connections...........4

3.2 Glow Behavior................................. 5

4. Environmental Conditions of Laboratory Experiments .............6 6

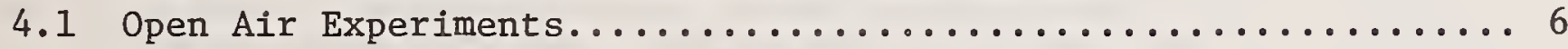

4.2 Simulated Building Wall Experiment.................... 7

5. Test Procedures and Quantification of Data.................. 7

5.1 Supply Voltages................................. 7

5.2 Circuit Currents............................... 8

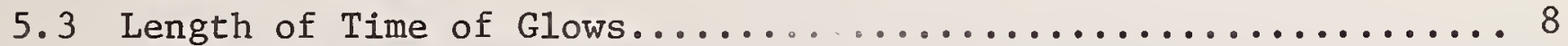

5.4 Resistance of Connections.......................... 9

5.5 Voltage Drop Measurements and Connection Power

Dissipation Calculations.......................... 9

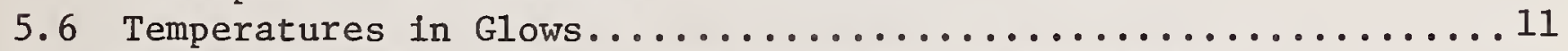

5.7 Temperatures at Points Other than at the Connection

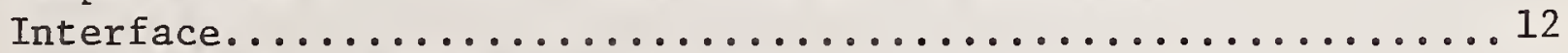

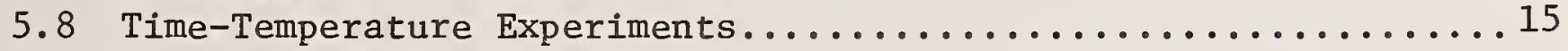

6. Effects of Glows on Circuit Loads and Circuit Protection Devices.... 18

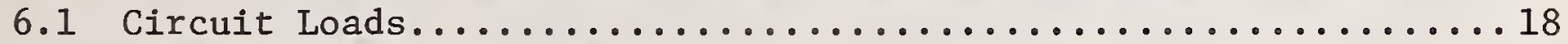

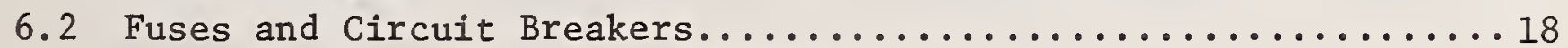

6.3 Ground Fault Circuit Interrupters..................... 18

7. Observed Results of Glows on Proximate Building Components......... 18

8. Other Investigations................................... 19

8.1 Loose Brass Wire-Binding Screw Investigations............... 19

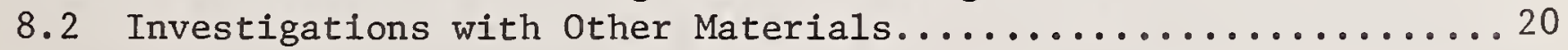

9. Discussion of Laboratory Data in This Report.................21

10. Field Existence of Glowing Electrical Connections...............21

11. Conclusions................................... 22

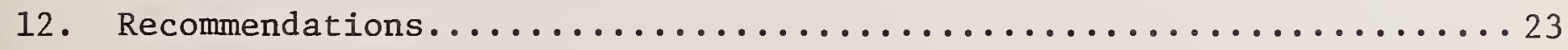

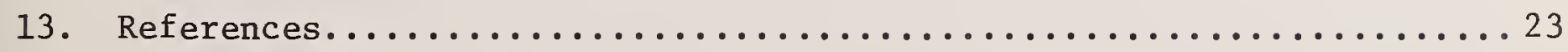





\section{INTRODUCTION}

In 1969 the U.S. Department of Housing and Urban Development initiated Operation BREAKTHROUGH; one of the purposes of the jrogram was to provide incentives to encourage and demonstrate innovations in housing. In the Operation BREAKTHROUGH program several innovations involving electrical connections in branch circuits were proposed. Approvals for innovations involving electrical systems installations were sparingly given with conservative stipulations, taking cognizance of the potential fire hazard and the concerns about lack of data for durability and other pertinent technical information. However, the possibilities of almost immediate significant economic benefits were recognized.

Subsequently, The U.S. Department of Housing and Urban Development agreed to sponsor, at the National Bureau of Standards, a long-term research project on electrical connections used in residential branch circuit wiring. The first two publications of this project were reports on "Analysis of Current Technology on Electrical Connections in Residential Branch Circuit Wiring" [1], and "A Preliminary Approach to Performance Requirements and Criteria for Electrical Connections in Residential Branch Circuit Wiring" [2]. This Report on glowing electrical connections is the third of this project.

After this project was under way for the U.S. Department of Housing and Urban Development, the National Bureau of Standards undertook another project for the Consumer Product Safety Commission concerning the safety of aluminum electrical wiring in residential use. Many of the technical aspects of the two projects were similar. Some preliminary information concerning glowing electrical connections was reported to the Consumer Product Safety Commission. Work on aluminum wire hazards for the Consumer Product Safety Commission was terminated before laboratory work for this report on glowing electrical connections was completed. Information concerning the work of NBS and others on aluminum wiring is contained in References [3] and [4].

The goals of the project for the U.S. Department of Housing and Urban Development are the development of performance criteria and test methods to evaluate electrical connections. As a result of laboratory investigations focused upon prevention and elimination of the glow condition and its deleterious effects, an influence upon performance criteria and test methods applied to electrical connections is anticipated. 


\subsection{Scope}

This report describes and characterizes the "glow" condition of electrical connections with laboratory-based data. The glow condition is differentiated from arcing or sparking which sometimes occurs in the process of making or breaking electrical circuits. Electrical and thermal data and the materials involved at the interface of glowing connections are presented and discussed. Also included are laboratory-obtained results concerning the overheating effects of glowing connections in a wall section with insulation, which simulated a common type of residential construction. However, it is not the intent of this report to develop interrelationships between temperatures and other conditions typical in buildings which contribute to electrical failure or fire.

No field studies have been carried out up to the present time to determine whether or not glowing electrical connections develop in actual residential branch circuits. However, the conditions required for glowing electrical connections are thought to be well within the realm of possibility in actual installations.

\subsection{Background}

As a prerequisite to the development of performance criteria and test methods to evaluate electrical connections, laboratory investigations were undertaken to determine quantifiable measures for "bad" electrical

connections by means of temperature measurements or wattage dissipation. These investigations included determining and identifying the mechanisms and environments that cause electrical connections to fail (so that failure may be prevented) in nominal 120 volt, 15 and 20 amp branch circuits. These investigations led to laboratory observations of glowing electrical connections. In the study and literature review resulting in the first report of this project [1] it was found that no published material on the glow condition was reported.

\subsection{Use of the Term "Glow" or "Glow Discharge" in Electrical Theory}

The terms "glow" and "glow discharge" are used by investigators of electrical phenomena, such as Windred [5], and Holm [6], in discussing phenomena associated with electric contacts. The use of term "glow" by such authorities refers to a transient condition which occurs in the process of and prior to the development of an arc or arc discharge.

\subsection{Definition of "Glow" as Used in this Report}

The glow referred to in this report is a sustained source of light and heat emanating from the vicinity of an electrical connection or from the vicinity of some other place in an electric circuit, such as where broken parts of a wire are in contact. Sometimes the glow is only a small spot in the interface of a connection. Sometimes a wire-binding screw, other conducting parts of a wiring device, and/or portions of the wire 
will glow. Sometimes a smaller and brighter spot can be observed in the interface between a wire and wire binding screw where other parts of the conducting path are glowing. The colors of or in the glow may be white, yellow, orange or red, depending on the temperatures. In S.ction 5.6 the relationship of color of glowing bodies to approximate temperatures is discussed.

\subsection{Wire-Binding Screw Materials}

While the glow condition is not limited to electrical connections with wire-binding screws, most of the quantified data on glowing electrical connections in this report were obtained with either copper or aluminum wire connected to receptacles with loose steel wire-binding screws. Wirebinding screws of currently available receptacles and other wiring devices are usually either steel or brass.

However, from a survey of local retail outlets, there appear to be more such devices available with steel screws than with brass screws. Wiring devices listed by Underwriters' Laboratories with the designation "CO/ALR" must have brass screws. It is the intent that aluminum wire be used only with "CO/ALR" wiring devices; copper wire may be (but is not required to be) used with such devices.

It is not obvious by looking at the screws on wiring devices whether they are steel or brass. All such screws are covered with a brass-colored plating for connection to "hot" (ungrounded) conductors, a silver-colored plating for connection to neutral (grounded) conductors or a green-colored plating for connection to grounding conductors. A magnet will readily determine if the screws are steel.

\section{DESCRIPTION OF ARCING/SPARKING IN ELECTRICAL CIRCUITS}

The purpose of this section is to distinguish the "glow" condition from "arcing/sparking" in electrical circuits. Although this section contains some very preliminary laboratory observations on arcing/sparking, the primary intent of including this information is to give the reader a more comprehensive understanding of the glow condition.

In the process of making or breaking an electric circuit, arcing or sparking may sometimes be observed. For example, arcs or sparks may occur when operating a switch or when inserting or withdrawing an attachment plug from a receptacle. In this report arcing/sparking connote transitory phenomena. Whether a form of repetitive arcing/sparking occurs in the "glow" was not determined.

In nominal 120-volt circuits it does not appear to be possible to maintain arcs or sparks or to have repetitive arcing/sparking other than momentarily, unless under load there is continual making and breaking of the circuit at some point in its current path. For example, with 
continuous vibration or other disturbance, repetitive arcing or sparking may occur between a loose wire and a terminal on a wiring device or at a broken point in the wire.

With repetitive arcing or sparking, high temperatures may occur in the vicinity, and if arcing or sparking continues for a considerable time, the hazard of overheating resulting in fire could probably occur. Whether vibration or other disturbances in a building could lead to repetitive arcing or sparking for other than a momentary period, or if there is much probability of this, is not known and was not evaluated. However, laboratory findings indicated that a "glow" may develop immediately, or at some later time after arcing or sparking has occured and the glow may remain sustained as long as the circuit in "on".

\section{DESCRIPTION OF THE GLOW CONDITION}

Section 1.4 defines the term glow as used in this report. The development of a glow at any particular time or under any particular circumstances, as well as the intensity of a glow, is not predictable. Because of this and because no published information describing the glow condition is known to the authors of this report, this section involving general laboratory observations is presented with the intent to give the reader a more comprehensive understanding of the general parameters involving the effects and behavior of the glow condition.

\subsection{General Parameters of Glowing Electrical Connections}

Every experimental attempt to obtain glows with loose steel wirebinding screws has been successful; over 100 such attempts, using both copper and aluminum wire, have been made. In the laboratory, glows have been established with only minimal pressure or force at the area of contact of a glowing connection. Glows have been established on steel wire-binding screws which were backed off one-eighth turn from a torque of 2 in-lbs. Glows were also produced in the laboratory where broken parts of an electric wire contacted each other.

In the laboratory the investigators were not able to obtain glows with tight electrical connections. However, if tight connections with steel wire-binding screws became loose, glows were readily obtained. Glows were obtained without any unusual environment, foreign substance, corrosion or surface coating. In these experiments the only physical parameters necessary to obtain and sustain glows were small contact area and/or small pressure at a contacting point in the conducting path. Torque/pressure, air gap dimensions, and contact area interrelationships were not systematically investigated. 
In these experiments the development of, extinguishment of, and intensity of glowing electrical connections were somewhat er atic. With time, glows were more likely to remain at approximately the same intensity if left undisturbed. Glows were developed along the side of wires where they interfaced with another part of the conducting path; such was the case with loose steel wire-binding screws. Glows were developed at the end of the wire; such was the case when the end of the wire contacted the head of a steel screw. Glows were also developed at the interface of broken parts of the wire. Sometimes glows were developed without vibration, wire disturbance or arcing. At other times they were developed by the disturbance created when an attachment plug was inserted in a receptacle. In other cases glows were only developed after severe vibration or other severe disturbance. In some cases glows appeared, disappeared, and reappeared many times.

Glows reappeared at the same point at times and in other instances at another point in the connection interface. In some cases glows shifted from one point in the interface to another without disappearing. Sometimes the entire wire-binding screw, other conducting parts of receptacles and portions of the wire near the connection glowed. At times when a glow was extinguished, after a short time the temperature was little more than that of a good connection.

Occasionally when a glow expired there was an open circuit. Sometimes with slight disturbance electrical continuity was restored and the glow randomly did and did not reappear.

Glows varied in intensity as the current in the circuit varied. For example, decreasing brightness was sometimes discernible to the eye when current was lowered from 15 amps to 12 and then to 10, 7, and 5 amps. In some instances the glow became brighter again as current was increased. In this series of laboratory tests some glows with 0.8 amp appeared to be brighter than some glows with 15 amps.

Glows, of course, expired when current was not flowing in the circuit. Sometimes after being off they immediately reappeared when current was turned on.

When power to the circuit is shut off, the two parts of the circuit in the vicinity of the glowing connection may or may not be connected by a small weld. The authors found in this study that when the circuit was off, a resistance meter sometimes indicated an open circuit at the binding screw and at other times indicated a conducting path whose resistance varied in different tests. This latter condition could indicate either a weld of small cross section or a non-welded contact of two surfaces. In either case, the glow could usually be reestablished without difficulty when power was reapplied to the circult.

The mechanism for the glow phenomena is not understood. However, from the test observations it is possible to consider an explanation. 
One can hypothesize the physical parameters of the glow phenomenon as follows: When a wire-binding screw on an electrical connector is backed off 1/8-turn from a tight position, an air gap ranging from zero to .0002 inch could be created somewhere between the circuit elements depending on the orientation of the wire. Since the dielectric strength of air is about $56 \mathrm{kV}$ (rms) per inch, an air gap smaller than about 0.002 inch could be breached at 120 volts. When voltage is applied to the circuit an arc is created at this gap or at some contact point of light pressure which is accompanied by high temperature, a glow, and perhaps some vaporized meta1. The exact location of the arc will be somewhat variable, because the location of the smallest air gap will depend on the unpredictable positions of the wire and binding screw. The presence of the glow is relatively stable, but not completely so, because the width of gap tends to be maintained physically by the binding screw.

As previously stated, glows were also produced in the laboratory where broken parts of an electric wire contacted each other. The test results suggest that actual air gap is not essential to the development of a glow, but that a small air gap or a contact of small area and relatively high electrical resistance is required to initiate a glow condition. Another investigator at NBS found that he could produce the glow condition when he closed a circuit by touching a wire to a steel nail. When the current was shut off, the wire and the nail were welded together and the nail could be lifted by raising the wire. This experiment was performed several times using both copper and aluminum wire with identical results.

In reference 8 , the author claims that a chemical breeding process of $\mathrm{Cu}_{2} \mathrm{O}$ occurs which is essential to the development of the heating mechanism in loose connections.

\section{ENVIRONMENTAL CONDITIONS OF LABORATORY EXPERIMENTS}

Data presented in this report were obtained with electrical connections exposed to open air or in a simulated, insulated wall of typical residential-type construction. Descriptions of the open air and simulated building wall experiments are described below. Test procedures used to obtain electrical and thermal data are described in Section 5.

\subsection{Open Air Experiments}

Many laboratory tests involving glowing connections were performed with connections open to the air in the laboratory where the heat produced by the connections was readily dissipated. Wiring devices (usually receptacles with steel wire-binding screws) were fastened in metal outlet boxes. The outlet boxes were fastened to a piece of wood which was rigidly held in place with a vise. Copper wires (非4 and 非2) and aluminum wires (非12 and 非10) were used in different experiments. Glowing connections could be readily observed by the investigators. Outlet boxes with removable sides were used. 
In order to obtain data under conditions simulating the actual installed use of connections in the field, some experiments vere performed in a simulated, insulated exterior wall of typical residential-type construction. In these experiments wall sections approximately 17 1/2 inches wide by 18 inches high and $45 / 8$ inches thick were constructed. The frame was constructed of nominal $2 \mathrm{x} 45 ;$ plywood ( $3 / 8$ inch) was fastened to the front and gypsum board ( $3 / 4$ inch) was fastened to the rear of the building wall section. The building wall section was filled with balsam wool (batts) insulation. Typical receptacle outlets were installed in the wall section. Both metal and plastic outlet boxes of typical dimensions (usually $2 \times 2 \times 3$ inches) meeting National Electrical Code requirements were used. Receptacles with steel wire-binding screws and aluminum (非12 and 非10) and copper.(非14 and 非2) wires were connected in various tests. Except for one or more purposely loose connections these experimental setups were made, as closely as possible, to simulate residential field installations.

\section{TEST PROCEDURES AND QUANTIFICATION OF DATA}

Data in this section of the report concerning the glow condition were principally obtained with either copper or aluminum wire and steel wire-binding screws on receptacles at the interface of loose connections in either open air or simulated building wall experiments as described in Section 4. Receptacles and other wiring devices are designed so that not only the screw but also a brass plate interfaces with the wire when a connection is made. Glowing connections were established with steel screws when the wire appeared to also be in physical contact with the brass plate on a wiring device.

\subsection{Supply Voltages}

\section{(a) Test Procedures}

Most laboratory investigations of the glow condition were made with supply voltages of 110 to $120 \mathrm{a}-\mathrm{c}, 60$ hertz. These are the characteristic parameters of residential branch circuits. However, to determine if supply voltages significantly affect the glow condition, attempts were made to establish glows with low voltage $a-c$ and low voltage $d-c$ power supplies.

(b) Results and Discussion

Glows were established with a-c supply voltages under 10 volts with approximately the same electrical (voltage drop) measurements recorded across the connection as when the same currents were used with a 110-120 volt supply. The resistance of electrical connections, even glowing connections, is small in comparison to the resistance of lights, appliances or other usual electrical loads on nominal 120-volt circuits. In the case 
of a low voltage supply, the resistance of a connection will represent a much larger part of the total resistance of the circuit. Therefore, glowing connections will have more effect on current and consequently voltage drop values with low voltage power supplies than with nominal 120-volt power supplies, unless other means to control current levels are employed.

If, prior to energizing a circuit, there is a high resistance at a bad connection, most of the avallable supply voltage will be across the connection instead of across the intended electrical load. In this case supply voltage may have an effect on investigations involving the glow condition.

Glows have also been established with low voltage d-c (under 10 volts) with approximately' the same electrical (voltage drop) measurements recorded when the same currents (15 amperes) were used with 110-120 volt, a-c supply. This appeared to indicate that the impedance in glowing connections was substantially all resistance.

\subsection{Circuit Current}

\section{(a) Test Procedures}

Current (amps, r.m.s.) was measured by an ammeter, and in some cases by an auto-ranging digital multimeter. Current was adjusted to various values by varying the electrical load and in some cases by varying supply voltage. In most cases, one to four adjustable 660-watt hot plates were used for the electrical load. In some cases light bulbs were used for the load or as part of the load.

\section{(b) Results and Discussion}

Visible glows, sustained for at least five minutes, have been observed with as little current as $0.3 \mathrm{amp}$, with many incremental values up to and over 20 amps in the circuit. A current of approximately 0.3 amp represents the electrical load of one 40-watt 1ight bulb. The ampacity (current carrying capacity in amperes) of most residential branch circuits does not exceed 20 amps. Visible glows were sustained for currents up to 50 amperes using low a-c supply voltage (under 20 volts).

\subsection{Length of Time of Glows}

\section{(a) Test Procedures}

In the laboratory, glows have been established both in open air and in simulated building wall experiments for many hours. To determine just how long a glow would last, current (15 amps) was applied to a glowing connection for an extended period. The glow was established with aluminum wire on a receptacle with steel wire-binding screws. The connection was in open air and with the test specimens under a laboratory hood. Voltage drop measurements were periodically recorded. 
The circuit with the glowing connection was turned on and off many times. It was never left on overnight and, therefore, never stayed on for more than about nine hours at any one time. At one time power was not applied to this circuit for three weeks. Then, when power was applied, the glow reappeared.

\section{(b) Results and Discussion}

From the measurements it was determined that the connection had glowed for 129 hours and that power dissipated in the glowing connection averaged approximately 20 watts for the 129 hours. At times in excess of 35 watts were dissipated.

When the experiment ended the connection had not failed in its ability to transmit current to the electrical load. About five inches of PVC insulation on the wire attached to the glowing connection, and considerable amounts of the non-metallic parts of the receptacle were gone. However, the wire and metal parts of the receptacle were intact. There appeared to be no pitting or burning away of metal parts, although there was discoloration of the surface of metal parts.

\subsection{Resistance of Connections}

In the report, the power dissipated at glowing connections (rather than resistance) is quantified. The tern "resistance" as used in this report requires some explanation. Resistance of a connection at a particular time may be determined by dividing the voltage drop across a connection by the current in the circuit. Such calculations show that the resistance of a glowing connection may be quite variable.

5.5 Voltage Drop Measurements and Connection Power Dissipation Calculations

\section{(a) Test Procedures}

Voltage drop measurements were made with a digital voltmeter. Power dissipated by an electrical connection was calculated by multiplying the circuit current by the voltage drop measured across the connection. When voltage drop measurements included substantial lengths of wire or other parts of the conducting path, the voltage drop of such components was measured and subtracted to obtain the voltage drop of the connection.

\section{(b) Results and Discussion}

Preliminary laboratory measurements indicated that voltage drop measurements, and hence determinations of power dissipated at a connection are substantially free of environmental effects. That is, determinations of power dissipated at connections are substantially the same in open air as they are in a simulated building wall, provided other factors, particularly current, are the same.

Voltage drop measurements (and subsequent power dissipation calculations) appear to be a more meaningful way than temperature measurements to compare the characteristics of electrical connections. 
Temperatures depend not only on heat generation but also on heat dissipation factors. However, temperature is the primary performance criterion concerning fire safety aspects. Therefore, there must be correlation between power dissipated by a connection and temperatures expected under actual installation conditions.

In tight, well-made electrical connections as well as in wire and other conducting components of electrical circuits, voltage drop will vary (substantially) directly with current. This is because resistance is substantially constant $(E=I R)$.

Power dissipated in a tight, well-made connection, as well as in wire and other conducting components of electrical circuits, will vary substantially with the square of current. (Power in watts $=E I=I 2 R$ ). With 10 amps in a circuit a tight, well-made connection will dissipate approximately 100 times the power that it will with one amp in the circuit.

Typical voltage drop measurements and calculations of power dissipated in tight well-made connections are listed in Table 1. These values are for comparison with values listed for glowing electrical connections in Table 2.

TABLE 1 - TYPICAL GOOD CONNECTIONS

$\begin{array}{ccc}\begin{array}{l}\text { CURRENT } \\ \text { (Amps) }\end{array} & \begin{array}{c}\text { VOLTAGE } \\ \text { DROPS } \\ \text { (Milivolts) }\end{array} & \begin{array}{c}\text { POWER } \\ \text { DISSIPATED } \\ \text { (Milliwatts) }\end{array} \\ 20 & 4-10 & 80-200 \\ 15 & 3-8 & 45-120 \\ 10 & 2-5 & 20-50 \\ 5 & 1-3 & 5-15 \\ 0.8 & 0.15-0.4 & 0.1-0.3\end{array}$

With 15 amps in a circuit, one foot of $\# 14$ copper or $\#_{12} 12$ aluminum wire will have a voltage drop of approximately 40 millivolts, and dissipate about 600 milliwatts. With 15 amps in a circuit, one foot of \#12 copper or \#10 aluminum wire will have a voltage drop of approximately 25 millivolts and dissipate about 375 milliwatts.

Voltage drop measurements and power dissipation calculations were repeatedly carried out in many experiments involving glowing connections in both open air and in simulated building wall construction. While glow behavior is quite unpredictable and difficult to quantify, it was observed from these experiments that higher voltage drops are apparently possible as the current in the circuit becomes smaller. This is opposite to experimental findings with good connections. However, in these experiments more power was generally dissipated as current increased. Power dissipated is proportional to the square of the current (power in watts $\left.=I^{2} R\right)$. Some typical voltage drop measurements and calculations of power dissipated in glowing connections are listed below: 
TABLE 2 - TYPICAL GLOWING CONNECTIONS

$\begin{array}{ccc}\begin{array}{l}\text { CURRENT } \\ \text { (Amps) }\end{array} & \begin{array}{c}\text { VOLTAGE } \\ \text { DROPS } \\ \text { (Mililvolts) }\end{array} & \begin{array}{c}\text { POWER } \\ \text { DISSIPATED } \\ \text { (Milliwatts) }\end{array} \\ 20 & 1000-2000 & 20,000-40,000 \\ 15 & 1200-2400 & 18,000-36,000 \\ 10 & 1500-3000 & 15,000-30,000 \\ 5 & 2000-4000 & 10,000-20,000 \\ 0.8 & 4000-7000 & 3,000-5,000\end{array}$

The range of values in Table 2 may be compared with values previously listed in Table 1 for good connections. It should be noted that with 20 amps in the circuit, power dissipated in glowing connections was sometimes 100 to 200 times that produced in a good connection; with 0.8 amps the corresponding difference was sometimes 10,000 to 20,000 times. (An electrical load of one 100-watt light bulb will give a circuit current of about 0.8 amps).

\subsection{Temperatures in Glows}

\section{(a) Test Procedures}

Temperatures in the glow of a glowing electrical connection are difficult to measure directly. Placing of thermocouples or other materials in the connection interface where the glow appears affects the characteristics of the glow. Non-contact methods of measurement ( $\mathrm{e}, g$. infrared thermography) would be necessary to obtain temperatures of the glow. Bramson [7] indicates that in measuring the temperature of nonblack bodies their emissivity must be taken into account. However, Branson states that "The optical properties of radiation in the visible spectral region have long been used to furnish approximate estimates for the temperature of glowing bodies from the color of their incandescence."

From Reference 7 (Bramson), it is indicated that when a body is heated to temperatures less than about $500^{\circ} \mathrm{C}\left(932^{\circ} \mathrm{F}\right)$ its radiation is not yet perceptible to the human eye. He states that when temperature of the body rises to $550-600^{\circ} \mathrm{C}\left(1022-1112^{\circ} \mathrm{F}\right)$ a faint glow appears and the outline of the heated body can be traced in darkness. At a somewhat higher temperature the heated body will exhibit a dark red tint and with further rise in temperature the radiation will change from dark red to red, orange, yellow and, white. However, the color scale depends on the selectivity of the radiation, and on the properties of the individual human eye.

Bramson summarizes the color of the incandescence by giving descriptions of the color at various stages as seen by various authors. These descriptions of color are given in Bramson's color scale, which is shown below. The authors referred to by Bramson are as follows: 
[2] William Platt Wood and J. M, Cork, Pyrometry, 2nd Edition, (New York, McGraw-Hill, 1941) pp. 263.

[3] Franz Rapatz, Die Ed El Sta Hle, 2. AUFL (Berlin, Springer, 1934) pp. 386.

[4] Otto Wawrziniok, Hand Buch Des Material Prufungswesens Fur Maschinen-Und Bauingernieure, 2 AUFL (Berling, Springer, 1923) pp. 700.

THE COLOR SCALE [7]

Color of incandescence according to various authors

$t,{ }^{\circ} \mathrm{C}$

470

600

650

700

750

800

850

900

950

1000

1050

1100

1150

1200

1300
[2]

Barely percep-

tible red

Dark red

Cherry red

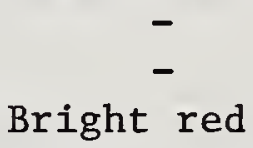

White
[3]

[4]
Dull brown

Brownish red

Dark cherry

Cherry

Bright cherry Dark cherry

Red

Bright red

Reddish yellow

Yellow

Bright yellow

Yellowish

white

White
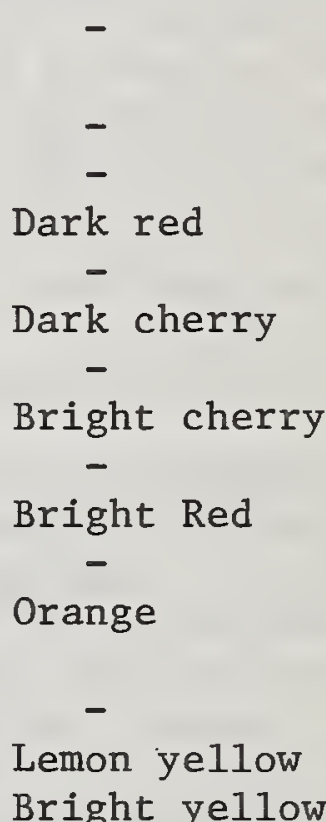

(b) Results and Discussion

By observing colors (according to Bramson's Color Scale) an approximation may be made of temperatures at various placed in, or in the vicinity of the glowing connection shown in the photograph at the back of this report. Note, however, there are considerable differences in the relationship of temperature to color by the various authors.

\subsection{Temperatures at Points Other Than at the Connection Interface}

\section{(a) Test Procedures}

In the laboratory thermocouples were used to record many temperatures, at various points on the conducting current path and at other locations being heated by glowing connections. Figure 1 identifies thermocouple locations referred to below. 


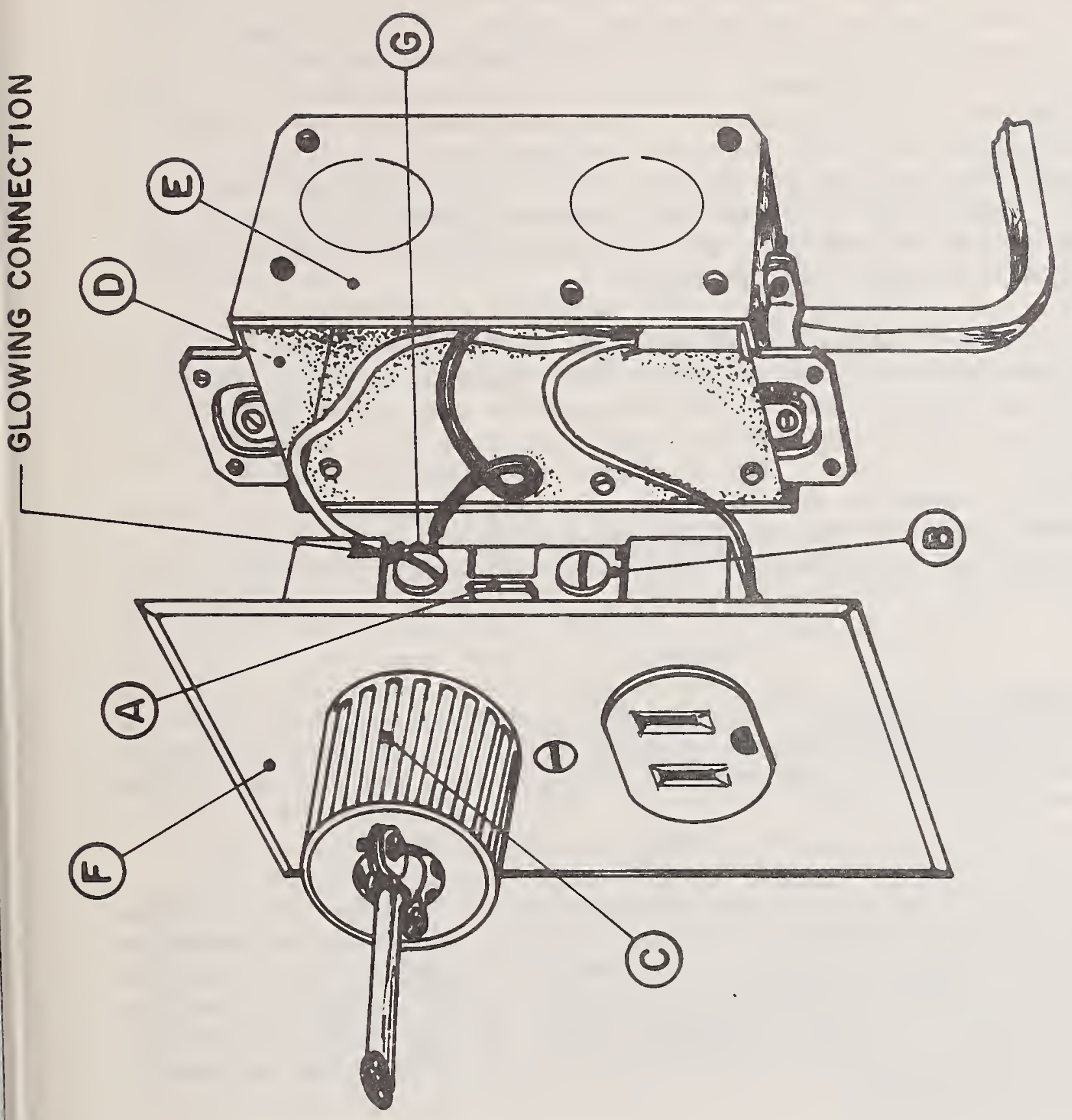

蛋

임

言嵒施急

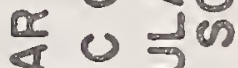

崖

2 क 2

$x+0$

$\infty$ a $\geq 0$

出㟧言可

。只站

山上

응

'⿺乚一

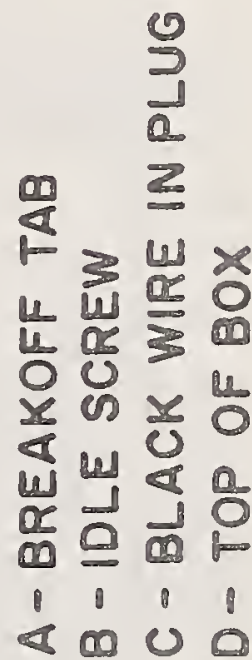


In an electric circuit the entire current path has some resistance and therefore increases in temperature when under electrical load. A resistance of about $12 / 3$ ohms per $1000 \mathrm{ft}$. occurs with $\# 12$ copper and \#10 aluminum wire. A resistance of about $22 / 3$ ohms per $1000 \mathrm{ft}$. occurs with $\#_{14}$ copper and $\|_{12}$ aluminum wire. The heat produced by a tight well-made connection will only increase temperatures very slightly near the connection when compared to temperatures at other points on the current path. The opposite is true with glowing connections where the heat produced by the current path is insignificant when compared with heat produced at the connection interface.

In open air experiments, on receptacles with tight connections, temperatures recorded on break-off tabs (See Figure 1) or other points on the current path near connections will usually range from $20^{\circ} \mathrm{F}$ to $35^{\circ} \mathrm{F}$ above ambient after equilibrium conditions have been reached with rated current in the circuit. Rated current is usually 15 amps in circuits with \#14 copper or $\# 12$ aluminum wire and 20 amps with $\|_{12}$ copper or \#10 aluminum wire. Thermal equilibrium conditions in open air experiments are usually reached or nearly reached within 30 minutes to one hour.

In a simulated, insulated building wall, temperatures near tight connection will not usually exceed $30^{\circ} \mathrm{F}$ to $50^{\circ} \mathrm{F}$ above ambient with rated current in the circuit. In a simulated building wall thermal equilibrium is not reached as quickly as it is in open air; equilibrium temperatures are usually reached in one or more hours in building walls.

With tight well-made electrical connections in a simulated building wall, temperatures of proximate building materials after thermal equilibrium, depend on various conditions. In some cases temperatures on steel outlet boxes may be $10^{\circ} \mathrm{F}$ to $15^{\circ} \mathrm{F}$ above ambient. However, one to two feet or more of wire (not including grounding wires) are usually in an outlet box and it is this wire, and not "good" electrical connections which generates most of the heat.

In open air experiments with glowing connections, temperatures recorded using thermocouples at points on the current path near the connections have exceeded $600^{\circ} \mathrm{F}$ within three minutes and $700^{\circ} \mathrm{F}$ within ten minutes after current was applied. (See Section 7 , Item 2 concerning effect on wire insulation.) Such points would include the break-off tab on receptacles with wire-binding screws or points on the wire very near ( $1 / 4$ to $1 / 2$ inch from) the glowing connections. Temperatures on the "idle" screw, (See Figure 1) have exceeded $600^{\circ} \mathrm{F}$ within five to ten minutes after current was applied. In open air experiments temperature measurements were not taken on components which were not a part of the 
current path. Because heat can dissipate rapidly, there appears to be little significance of such measurements.

\subsection{Time-Temperature Experiments}

\section{(a) Test Procedures}

Experiments were made with glowing electrical connections to obtain time-temperature data at various points on electrical and proximate building components of electrical installations in a simulated exterior residential wall. Section 4.2 describes the type of construction used in these experiments. This data when combined with the information in Section 7 concerning the observed effects of glowing connections on proximate building components gives an indication as to the hazards which may be involved.

\section{(b) Results and Discussion}

Figures 2 and 3 present results of two experiments involving loose steel wire-binding screws, one in which copper wire was used and one in which aluminum wire was used. Figure 1 illustrates thermocouple locations of temperature measurements which are plotted in Figures 2 and 3 . It should be noted that laboratory experiments did not indicate any substantial difference in the thermal performance between copper and aluminum wire with glowing electrical connections. However, it must be realized that these data are not statistically large enough to compare copper with aluminum wire when electrical connections are glowing.

It should be noted that the graphs illustrate typical data which can be obtained with glowing connections. Because of the erratic behavior which may be typical of glowing connections (see Section 3.2), other experiments in which all parameters are repeated as closely as possible may result in somewhat different time-temperature data. From other limited laboratory experiments, temperatures shown on the graphs (Figures 2 and 3) however, are not extreme but are typical. Also, quickly rising temperatures on the current path at points near the connection and more slowly rising temperatures at points on other components are typical.

It should be noted that in the experiment involving copper wire (Figure 3) a ground fault circuit interrupter (GFCI) which was used for laboratory safety operated twice opening the circuit. (In the process of insulation deterioration either a "hot" or neutral conductor came in contact with the grounding wire or with some object which was in contact with the grounding wire). The GFCI did not operate during the experiment with aluminum wire. (Figure 2). Operation of GFCIs is a chance occurrence, which can occur in laboratory or field installations with either copper or aluminum wire. The GFCI was removed from the circuit, permitting the experiment to proceed. Having a GFCI on most branch circuits is, at the present time, not common practice. 


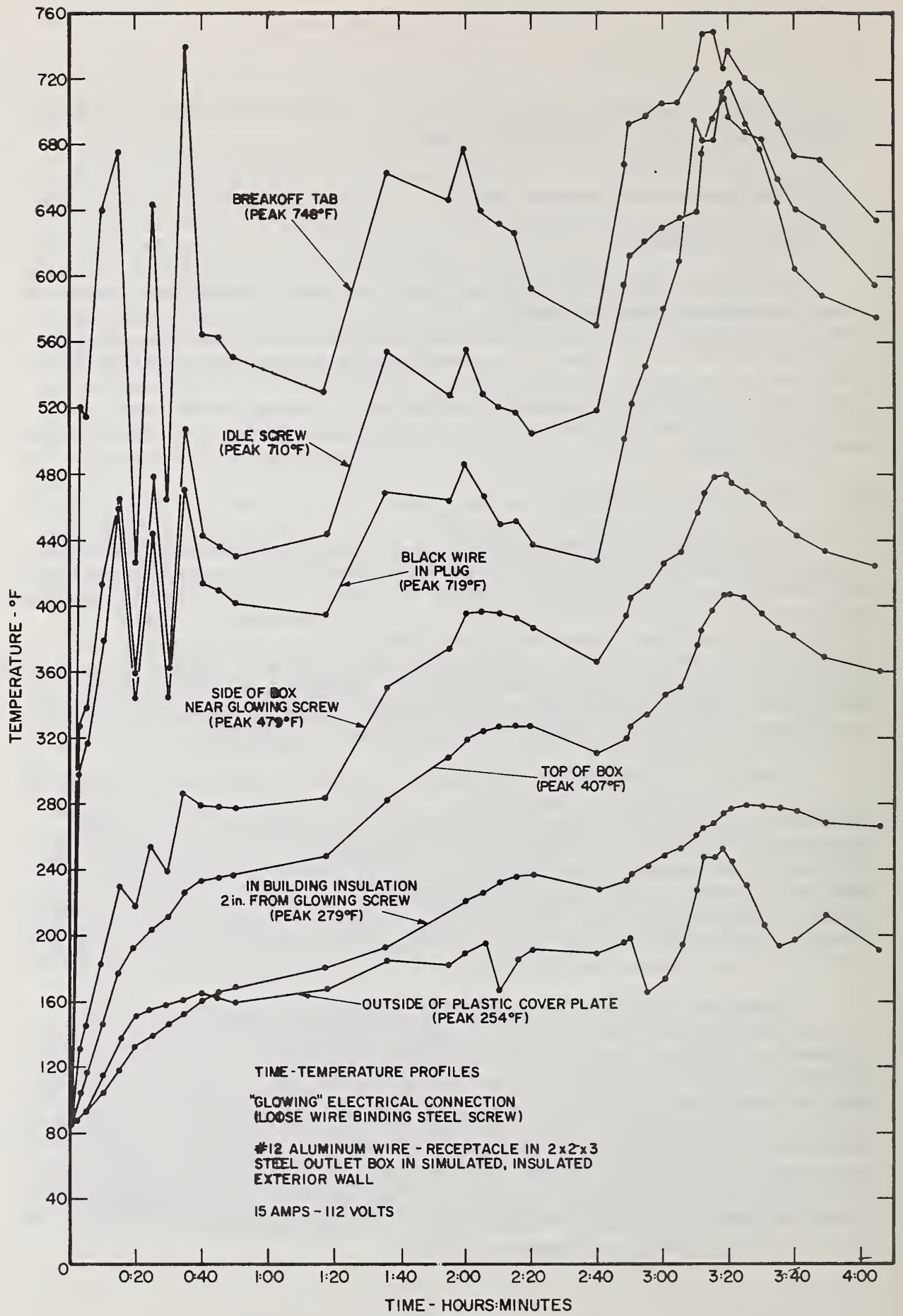




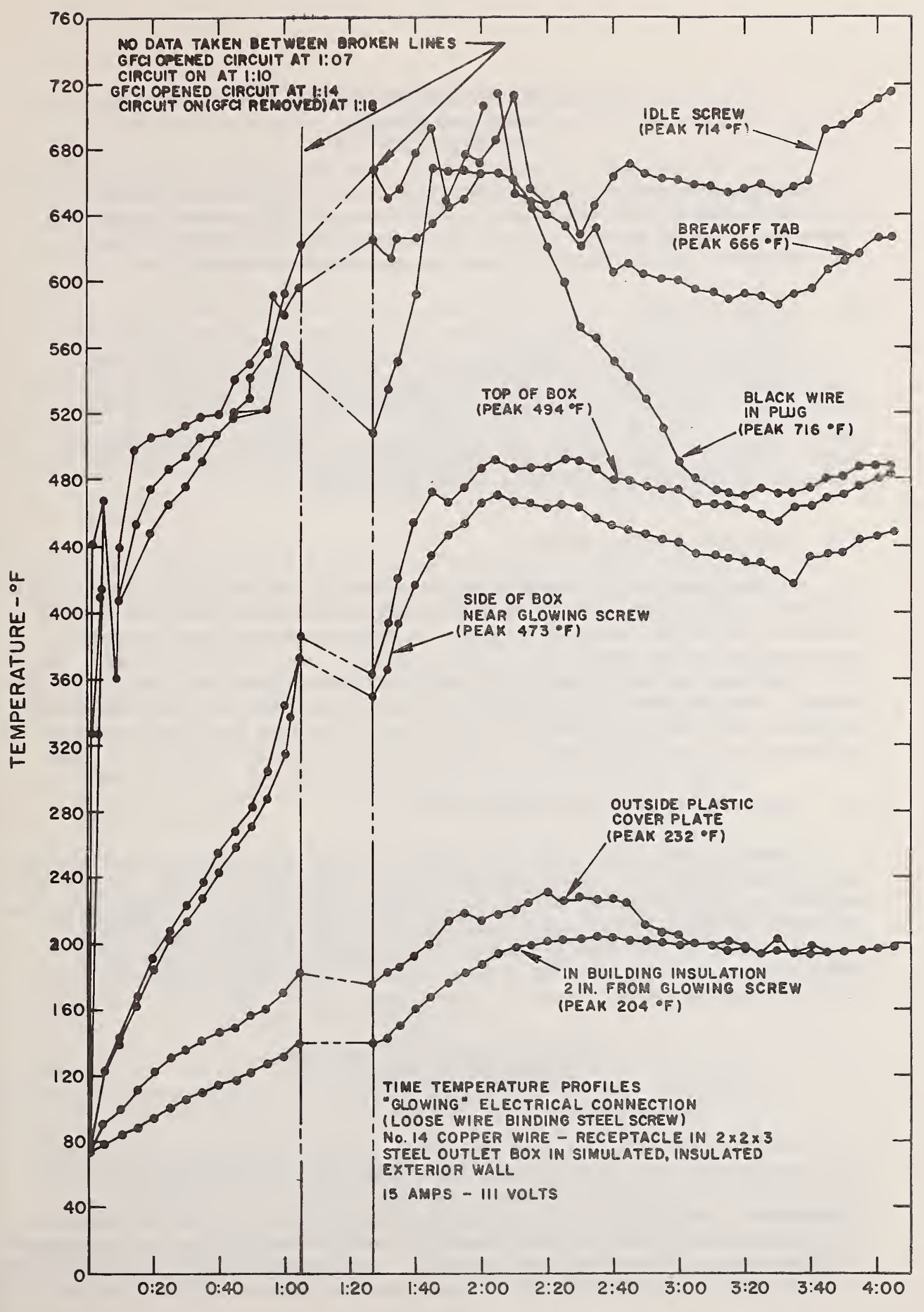

TIME-HOURS: MINUTES

FiquT 3-EFFECTS OF GLOWING ELECTRICAL CONAECTION-COPPER WIRE 


\section{EFFECT OF GLOWS ON CIRCUIT \\ LOADS AND CIRCUIT \\ PROTECTION DEVICES}

During the course of the laboratory investigations described in Section 5, the effect of glowing connections on (1) circuit 1oads, (2) fuses and circuit breakers, and (3) ground fault circuit interrupters was observed. These observed results are discussed below.

\subsection{Circuit Loads}

Glowing electrical connections will not perceptibly affect the performance of lights, appliances or other electrical loads. Glows will reduce the voltage to the circuit load from less than one to up to approximately 7 or 8 volts. Except under very unusual circumstances, such reduced voltages would go unnoticed in (nominal 120-volt) electrical circuits in residences and most other buildings.

\subsection{Fuses and Circuit Breakers}

Glowing electrical connections will not "blow" fuses or trip circuit breakers. Fuses and circuit breakers operate when current in a circuit exceeds some value, such as 15 amps. A glowing connection, in effect, adds load in series with lights, appliances or other circuit loads; it will decrease current slightly. Only if the glow produces some secondary effect, such as when deteriorating insulation allows the "hot" electrical conductor to contact the neutral conductor, (causing what is sometimes referred to as a "dead short"), will fuses or circuit breakers operate.

\subsection{Ground Fault Circuit Interrupters}

Glowing electrical connections will not operate ground fault circuit interrupters (GFCIs), except as noted below. GFCIs will only operate if current at some point in the circuit goes to ground. A glowing connection in effect becomes a secondary electric load with no current going to ground. Only if the glow produces some secondary effect, such as deteriorating insulation, which then allows either the"hot"conductor or the neutral conductor to contact a grounded object, will GFCI's operate.

\section{OBSERVED RESULTS OF GLOWS ON PROXIMATE BUILDING COMPONENTS}

Some effects of glowing connections, were observed during both open air (see Section 4.1) and simulated building wall (see Section 4.2) experiments. Highlights of these observed results are listed below. Systematic attempts to evaluate and relate glow characteristics, such as temperature or connection power dissipation to fire starting on proximate building components were not undertaken. Additional laboratory work should be performed on this aspect to characterize the potential fire hazard. 
1. Combustible material, including wood, paper and balsam wool insulation, in contact with glowing connections readily ignited.

2. In open air and in simulated building walls, the PVC insulation on the wire attached to loose wire-binding screws was completely consumed for a distance of four or five inches. Until there was a considerable portion of the wire exposed, smoke or gas from the insulation was observed.

3. In a simulated building wall, approximately one-third of the non-metal parts of receptacles with a glowing connection were completely consumed with the metal current path still performing its function. Considerable portions of non-metal parts of receptacles in open air experiments also were consumed.

4. Considerable insulation material on attachment plugs, which were in receptacles with glowing connections, was consumed; such plugs were badly deformed and on some occasions have ignited.

5. In simulated building wall experiments considerable charring of wood paneling and balsam wool insulation has occurred. These building components were outside of steel outlet boxes housing glowing connections.

6. In simulated building walls non-metallic outlet boxes housing glowing connections were charred through and were greatly deformed.

7. Plastic cover plates on the wall of simulated building wall experiments have charred through and were observed to be visibly red hot.

8. Pillow cases placed against receptacles with cover plates attached in simulated building wall experiments "scorched through." In such cases "scorching" first occurred opposite the holes in the receptacle where the prongs of attachment plugs are intended to enter.

\section{OTHER INVESTIGATIONS}

Preliminary laboratory investigations were made with materials where no steel was present at the interface of electrical connections. Results of these preliminary investigations are discussed below.

\subsection{Loose Brass Wire-Binding Screw Investigations}

Repeated attempts with over 20 connections were made in the laboratory to develop glows on wiring devices with loose brass wire-binding screws, using both copper and aluminum wire. None of these attempts were successful even with considerable vibration or wire disturbance. Continual vibration 
or wire disturbance with either copper or aluminum wire on devices with loose brass screws resulted in repeated arcing or sparking and high temperatures. In fact, it appears that with vigorous wire disturbance, higher temperatures can be developed on brass screws than on steel screws because it was possible to melt aluminum wire on brass screws. In these tests it was not possible to melt aluminum wire with steel screws.

Explanations of the repeated arcing or sparking conditions, whereby the effects appear to be more severe with brass than with steel, were not explored further. The significance of this experimentation is that glows did not develop with loose brass wire-binding screws after the vibration or wire disturbance ceased. Also, voltage drop and temperature measurements indicated values which were not substantially above those of tight connections, as shown in Table 1. However, investigations in other laboratories indicate that connections with brass wire-binding screws have overheated without wire disturbance.

\subsection{Investigations with Other Materials}

Subsequent experimentation was performed with common materials which may be in contact in electric circuits. Some of these experiments simulated broken wire with the broken ends in contact. In every case an electric current of 15 amps was used.

Glows were established and sustained for at least five minutes at the interface between the following materials.

1. Copper wire and steel block

2. Aluminum wire and steel block

3. Copper wire and aluminum wire

4. Copper wire and copper wire

5. Aluminum wire and aluminum wire

With repeated attempts glows were not established between either copper wire and brass blocks or between aluminum wire and brass blocks. The brass and steel blocks used were approximately $1 / 4^{\prime \prime} \times 2^{\prime \prime} \times 2^{\prime \prime}$ and were inserted in the conducting paths of the circuits. Contacts were made between the ends of wire and the $2^{\prime \prime} \times 2^{\prime \prime}$ surface of blocks. Wire to wire contacts were made at the ends of the wires.

Repetitive arcing will readily continue between either copper and brass or aluminum and brass as long as there is disturbance at the interface. However, after the disturbance ceased, electrical and temperature measurements indicated that either an open circuit or a relatively good contact existed. Considerable experimentation and analysis would be necessary to establish scientific explanations. It should be noted that steel is not necessary to establish glowing interfaces: however, the failure to obtain glows with brass is quite peculiar and should be investigated further. 


\section{DISCUSSION OF LABORATORY DATA IN THIS REPORT}

These laboratory investigations were of an exploratory lature in an area where no published reference information was found. However, these data are believed to warrant significant conclusions on some aspects of the effects of the glow phenomenon.

The data presented in this report cover a wide range of conditions since fine details were not intially of interest. The range of voltage drops and temperatures relating the difference between glowing connections and good connections are so great that precise laboratory procedures will not greatly affect the significance of the data presented. For example, with 15 amps in the circuit, the break-off tab (see Figure 1 ) on a receptacle with good connections may attain temperatures on the order of 30 to $50^{\circ} \mathrm{F}$ above ambient. However, the break-off tab on a receptacle with one glowing connection may, within two or three minutes, reach 300 to $600^{\circ} \mathrm{F}$ above ambient. (See Figures 2 and 3)

Quantified data presented in Section 5 of this report reflects information which has been obtained in the laboratory. Data reflecting approximate extreme measurements which could be readily obtained are given. For example, with 15 amps in the circuit, sustained glows have been established with voltage drops on the order of $21 / 2$ volts across the connection. Whether glows can be established at the same current level with voltage drops on the order of 5 or more volts, for which the wattage dissipation and hence the potential fire hazard would be much greater, is not known. The authors have been unable to establish glows with voltage drops of such magnitude with 15 amps in the circuit. Sustained glows with voltage drops of 5 to 7 volts have been established with one amp or less in the circuit.

\section{FIELD EXISTENCE OF GLOWING ELECTRICAL CONNECTIONS}

Glowing electrical connections may possibly be the cause of some electrical failures in the field; fires have been started in the NBS laboratory from glowing connections. Conditions necessary to establish glowing electrical connections probably exist in many residential and other buildings. Review of the transcript proceedings of hearings by the Consumer Product Safety Commission on aluminum wire problems disclosed instances such as "a hot outlet into which nothing was plugged" and also numerous citings on loose connections. Reference 3 contains an abstract of these hearings.

Field studies have not been undertaken to establish the frequency of loose connections in field branch circuits, or whether or not the glow phenomenon develops in the field. NBSIR 75-723 [3] in discussing tests made on receptacles removed from a house in which a fire attributable to aluminum wiring occurred states: "Of the 6 receptacles tested (24 screw terminals) 12 connections were loose to the point where it was difficult if not impossible to measure a stable value of resistance. This seemed to be more true of receptacles wired with the heavier gauge 非10 wires 
than those wired with 1312 wire. It could be inferred that at least part of the problem is the increased stiffness of the heavier wire which is more likely to be loosened when stuffed into a receptacle box." However, a substantial field study would be required to obtain statistically valid information on loose or overheating electrical connections.

\section{CONCLUSIONS}

1. Glowing electrical connections appear to be most likely at coppersteel or aluminum-steel interfaces. Many wiring devices have steel wire-binding screws. Glows may develop at such interfaces even when there appears to be physical contact between the wire and a brass plate on wiring devices.

2. Glowing electrical connections may exist for protracted periods of time (hours, days, months) without breaking the electrical circuit.

3. In these experiments a glow was not developed in connections when there was only a copper-brass or aluminum-brass interface.

4. Glows have been established where no steel existed. Specifically glows have been established between contacting ends of copper wires, between contacting ends of aluminum wires and between copper and aluminum wires.

5. Glowing electrical connections may occur over nearly the entire range of current likely to be present in residential branch circuits.

6. With loose connections or where broken wires contact each other glows may occur.

7. Glowing electrical connections will not operate fuses, circuit breakers or ground fault circuit interrupters unless the glow causes a secondary effect (See Section 7).

8. Glowing electrical connections will not perceptibly affect the performance of lights, appliances or other electrical loads.

9. In loose connections with copper-brass or aluminum-brass interfaces, repetitive arcing or sparking may lead to overheating.

10. Combustible material in contact with glowing electrical connections can ignite.

11. Glowing electrical connections in simulated building walls may heat proximate building materials to above their ignition temperatures. 


\section{RECOMMENDATIONS}

Considerations should be given to establishing the extent ( $F$ potential hazards from glows developing in existing buildings and additional laboratory research undertaken to provide resolution of glow phenomena.

1. Research addressing realistic installations and practices involving glowing electrical connections should be undertaken, toward the following objectives:

A. Advance quantification of characteristics of glowing connections presented in this report.

B. Scientifically explain reasons for the glow condition.

C. Determine how electrical connections become loose (creep, thermal expansion and contraction, stress relaxation, corrosion, installation procedures, etc.) and determine whether any other mechanisms may lead to the glow condition.

D. Investigate and quantify data concerning loose brass screws; determine if there are conditions under which copper-brass and aluminum-brass interfaces will develop glows or otherwise overheat under static conditions.

E. Explore the possibility of using a portable device to quickly determine the quality of electrical connections in houses or other buildings.

F. Obtain statistically significant field data on the quality (voltage drop, power dissipation) of electrical connections.

G. In a systematic manner, characterize the fire starting potential of glowing electrical connections in typical types of building wa1ls.

2. Criteria and tests or other evaluative procedures should be developed and regulations put into effect which will ascertain that electrical connections installed in the future will not be vulnerable to the glow or to other overheating conditions.

3. Determine modifications which can be taken to lessen the vulnerability of existing electrical connections to the glow or other overheating conditions and determine if such modifications are feasible from both technical and economic standpoints.

\section{REFERENCES}

[1] Analysis of Current Technology on Electrical Connections Used in Residential Branch Circuit Wiring, BSS 63, National Bureau of Standards, William J. Meese and Ramon L. Cilimberg, March 1975. 
[2] A Preliminary Approach to Performance Requirements and Criteria for Electrical Connections in Residential Branch Circuit Wiring, NBSIR 75-672, National Bureau of Standards, William J. Meese, Ramon L. Cilimberg and Adolfo A. Camacho, March 1975.

[3] Aluminum Branch Circuit Wiring in Residences; Summary Report for the Consumer Product Safety Commission, January-September 1974, NBSIR $75-723$.

[4] Hazard Assessment of Aluminum Electrical Wiring in Residential Use, NBSIR 75-677, January 1974, E. Bunten, J. Donaldson, and E. McDowel1.

[5] Holm, Ragnar, Electric Contacts Theory and Application, SpringerVerlog, New York, Inc., 1967.

[6] Windred, G. Electrical Contacts, McMillan, and Co., Ltd., London, 1940.

[7] Bramson, Mikael A., Infrared Radiation, A Handbook for Applications, (Institute of Mineral Fuel, Academy of Sciences of the USSR, Moscow) Plenum Press, New York, 1968.

[8] Kawase, Taro, Chiba University, Dept. Electrical Engineering, Chiba, Japan. Attachment Report to Letter of May 6, 1975, to Mr. R. Simpson, Chairman, CPSC. 
NBS-114A (REV. 7.73)

\begin{tabular}{|c|c|c|c|}
\hline $\begin{array}{l}\text { U.S. DEPT. OF COMM. } \\
\text { BIBLIOGRAPHIC DATA } \\
\text { SHEET }\end{array}$ & $\begin{array}{l}\text { 1. PUIBLICATION OR RIPPORT NO. } \\
\text { NBSIR 76-1011 }\end{array}$ & $\begin{array}{l}\text { 2. Gov't Accession } \\
\text { No. }\end{array}$ & 3. Recipient's Accession No. \\
\hline \multirow{2}{*}{\multicolumn{3}{|c|}{ EXPLORATORY STUDY OF GLOWING ELECTRICAL CONNECTIONS }} & $\begin{array}{l}\text { 5. Publication Date } \\
\text { November } 1976\end{array}$ \\
\hline & & & 6. Performing Organization Code \\
\hline \multicolumn{3}{|c|}{$\begin{array}{l}\text { 7. AUTHOR(S) } \\
\text { William J. Meese and Robert W. Beausolie1 }\end{array}$} & 8. Performing Organ. Report No. \\
\hline \multicolumn{3}{|c|}{$\begin{array}{l}\text { 9. PERFORMING ORGANIZATION NAME AND ADDRESS } \\
\text { NATIONAL BUREAU OF STANDARDS } \\
\text { DEPARTMENT OF COMMERCE } \\
\text { WASHINGTON, D.C. } 20234\end{array}$} & 10. Project/Task/Work Unit No. \\
\hline \multicolumn{3}{|c|}{$\begin{array}{l}\text { 12. Sponsoring Organization Name and Complete Address (Street, City, State, ZIP) } \\
\text { Office of Policy Development and Research } \\
\text { The Department of Housing and Urban Development } \\
\text { Washington, D.C. } 20234\end{array}$} & $\begin{array}{l}\text { 13. Type of Report \& Period } \\
\text { Covered } \\
\text { FINAL } \\
\text { 14. Sponsoring Agency Code }\end{array}$ \\
\hline
\end{tabular}

15. SUPPLEMENTARY NOTES

16. ABSTRACT (A 200-word or less factual summary of most significant information. If document includes a significant bibliography or literature survey, mention it here.)

This report describes and characterizes with quantifiable electrical and thermal measures the extent to which loose electrical connections in residential-type branch circuits have overheated in the laboratory. With loose electrical connections, which conceivably could be inadvertently duplicated in field installations, but with otherwise normal installation and operating conditions, visible glows have been observed under laboratory test conditions in nominal 120-volt, 15. and 20 ampere branch circuits with both copper and aluminum wire. Characteristics of the glow condition are differentiated from arcing/sparking as sometimes observed in making or breaking electric circuits.

Glowing electrical connections may dissipate as much as 35 watts of power with a current of 15 amps in the circuit and as much as 5 watts with a current of 0.8 amp in the circuit. Temperatures over $750^{\circ} \mathrm{F}$ were measured on the "break-off tab" of receptacles. Metal outlet boxes housing glowing connections in an insulated wall test set-up representative of a common type of residential construction attained temperatures in excess of $450^{\circ} \mathrm{F}$. In laboratory tests under repetitive, intermittent and periodic cycles, a connection on a steel wire-binding screw of a receptable open to the air had sustained glow conditions maintained for over 100 hours. Glowing connections will not perceptibly affect the electrical performance function of lights, appliances or other electrical loads, and will not "blow" fuses, trip circuit breakers or operate ground fault circuit interrupters.

17. KEY WORDS (six to twelve entries; alphabetical order; capitalize only the first letter of the first key word unless a proper name; separated by semicolons)

Key Words: Arcing/sparking; branch circuit; contact resistance; electrical connections; fire hazard; glowing electrical connections

— For Official Distribution. Do Not Release to NTIS

— Order From Sup. of Doc., U.S. Government Printing Office Washington, D.C. 20402, SD Cat. No.C13

\begin{tabular}{|l|c|}
\hline $\begin{array}{l}\text { 19. SECURITY CLASS } \\
\text { (THIS REPURT) }\end{array}$ & $\begin{array}{c}\text { 21. NO. OF PAGES } \\
\text { UNCLASSIFIED }\end{array}$ \\
\hline $\begin{array}{l}\text { 20. SECURITY CLASS } \\
\text { (THIS PAGE) } \\
\text { UNCLASSIFIED }\end{array}$ & $\begin{array}{l}\text { 22. Price } \\
\$ 4.00\end{array}$ \\
\hline
\end{tabular}

XOrder From National Technical Information Service (NTIS) Springfield, Virginia 22151 
